\title{
Research and Evaluation for Passive Safety System in Low Pressure Reactor
}

\author{
Peng Chuanxin, Zhuo Wenbin, Chen Bingde, Nie Changhua, and Huang Yanping
}

Nuclear Power Institute of China, Chengdu 60041, China

Correspondence should be addressed to Peng Chuanxin; xingxing322@163.com

Received 6 December 2013; Revised 23 March 2014; Accepted 15 July 2014

Academic Editor: Shengqiang Li

Copyright (C) 2015 Peng Chuanxin et al. This is an open access article distributed under the Creative Commons Attribution License, which permits unrestricted use, distribution, and reproduction in any medium, provided the original work is properly cited.

Low pressure reactor is a small size advanced reactor with power of $180 \mathrm{MWt}$, which is under development at Nuclear Power Institute of China. In order to assess the ability and feasibility of passive safety system, several tests have been implemented on the passive safety system (PSS) test facility. During the LOCA and SBO accident, the adequate core cooling is provided by the performance of passive safety system. In addition the best-estimate thermal hydraulic code, CATHARE V2.1, has been assessed against cold leg LOCA test. The calculation results show that CATHARE is in a satisfactory agreement with the test for the steady state and transient test.

\section{Introduction}

The use of passive safety systems eliminates the costs associated with the installation, maintenance, and operation of active safety systems that require multiple pumps with independent and redundant electric power supplies [1]. As a result, passive safety systems are being considered for numerous reactor concepts, such as AP600/AP1000 [2], APR1400 [3], APWR+ [4], SMART [5], IRIS [6], and MASLWR [7].

The AP600 was the first passively safe nuclear plant to be certified in the United States. It employs passive safety systems that rely on gravity (core make-up tank, in-containment refueling water storage tank), compressed gas (accumulator), natural circulation (passive residual heat removal heat exchanger), and evaporation to provide for long-term cooling in the event of an accident.

The certification of AP600/AP1000 was based on comprehensive integral system and separate effects testing conducted by Westinghouse and the US Department of Energy at the SPES test facility in Italy and at the APEX test facility at Oregon State University. The purpose of SPES-2 tests was to simulate AP600 response to postulated accident events and to validate safety analysis codes [8]. The second integral facility APEX emphasized the depressurization, IRWST injection, and long-term cooling during small break LOCA [9]. Besides, US NRC conducted independent integral test programs at
ROSA in Tokai-mura, Japan, focusing on the high pressure and depressurization phase, the initiation of IRWST injection [10], and the passive residual heat removal [11].

Low pressure reactor is a small size advanced reactor with power of $180 \mathrm{MWt}$, which is under development at Nuclear Power institute of China. The primary system of reactor consists of a reactor pressure vessel, four loops, and the tank. Each loop is made up of heat exchanger and reactor coolant pump, hot leg and cold leg, and so forth. The reactor produces $200,000 \mathrm{~m}^{3}$ /day of hot water $\left(90^{\circ} \mathrm{C}\right)$ for low temperature seawater desalination. The low pressure reactor operates at low temperature (temperature at the outlet is $98^{\circ} \mathrm{C}$ ) and atmospheric pressure (pressure at the top of tank is $0.1 \mathrm{MPa}$ ). It follows that the consequences of accidents are less severe than typical PWR. In addition, it adopts passive engineered safety systems such as emergency core cooling system and passive residual heat removal system to mitigate consequences of accidents. Figure 1 shows the schematic diagram of the low pressure reactor. The tank is a significant component of low pressure reactor, which is a very large pool filled with cold borated water with a volume of $1310 \mathrm{~m}^{3}$. During the normal operation, the tank is used to maintain the primary system pressure. And during the shutdown or non-LOCA, tank is treated as heat sink for the core decay heat. Another important role of the tank is to provide water source for core injection if LOCA occurs. As the operational 


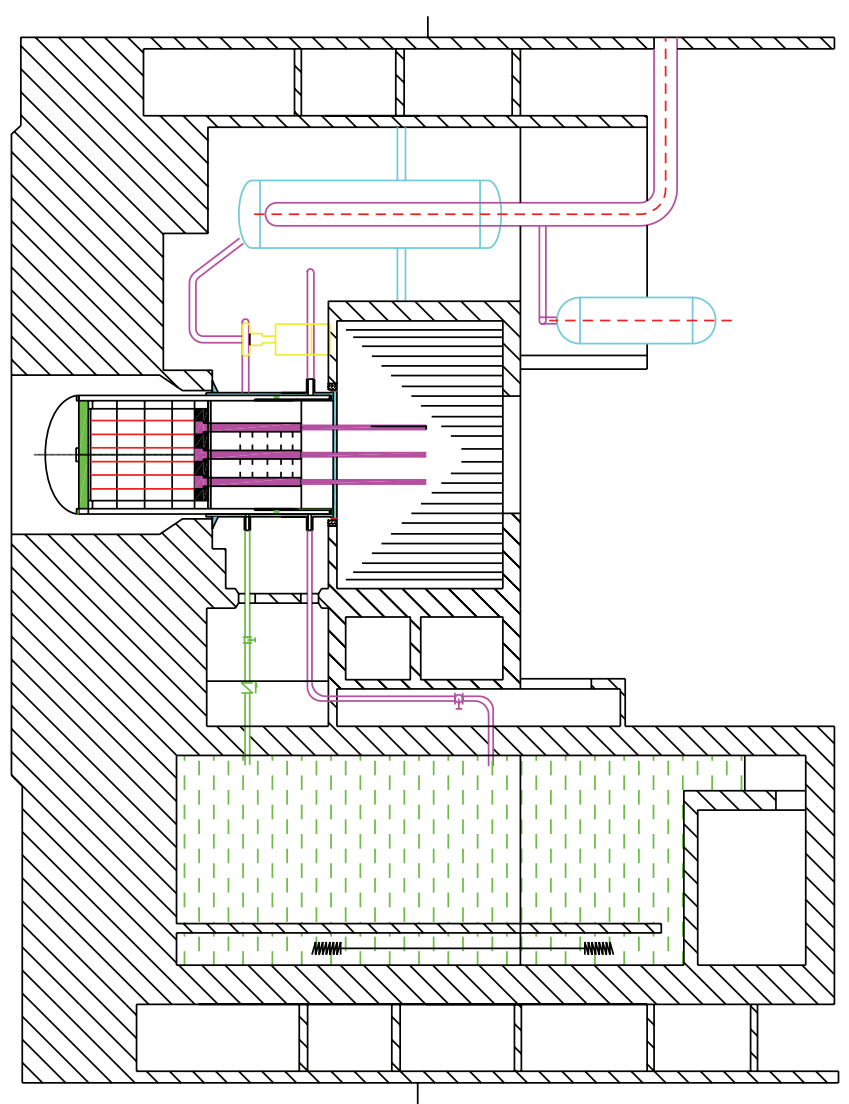

FIGURE 1: Schematic diagram of low pressure reactor.

pressure is about $0.4 \mathrm{MPa}$, the head pressure of the water in the tank is adequate for core injection. Therefore the design of Accumulator and Automatic Depressurization System is not necessary for the low pressure reactor.

In order to assess the ability and feasibility of low pressure reactor passive safety system, several tests have been implemented on the passive safety system (PSS) test facility [12]. In this paper the experimental investigations on the characteristics of the passive safety systems under LOCA and $\mathrm{SBO}$ are reported in detail. In addition the experimental data are used to assess CATHARE simulating the cold leg LOCA test.

\section{Passive Safety System Test Facility}

The passive safety system test facility is employed to simulate various accidental scenarios (such as loss-of-coolant accident and station black-out accident) that might occur in the low pressure reactor. To preserve the similar thermal hydraulic transients, the PSS facility has a geometrical scaling ratio of $1 / 1$ in length and height and 1/45 in volume, and it operates at full pressure and temperature conditions of prototype [13]. Table 1 shows the scaling ratios of the facility to the low pressure reactor for some major geometrical and thermal hydraulic parameters. The schematic diagram of PSS facility is shown in Figure 2. And its main features are summarized as follows.
(1) The reactor vessel is simulated by the core simulation vessel and downcomer annulus simulation vessel. A total number of 96 electrically heated rods with a maximum total power of $600 \mathrm{~kW}$ are installed in the core simulation vessel. The break simulating system consists of a quick open valve, a venturi flow meter, and the core external cavity simulation vessel. The break flow rate was directly measured with a venturi flow meter. The venturi flow meter was installed at the upstream of the break nozzle for the break flow to be single-phase water flow at the measurement location. The accumulated water in the core external cavity simulation vessel shows good agreement with the break flow rate measured by venturi flow meter.

(2) The PSS test facility is designed to be operated by a combination of manual and automatic operations. The controlled components include the electrically heated rod, the primary coolant pump, the primary loop flow control valve, and the heat exchanger cooling water flow control valve. All the safety related accidents should be initiated and controlled by automatic control logics as they require automatic reactor trip logics to initiate the passive core cooling systems and the passive residual heat removal system. The corresponding trip logics, tables, and set points are programmed to control a sequence of events.

(3) The data acquisition system involves 55 instruments to measure system pressure, differential pressure, fluid temperature, water level, and flow rate. The precision of nickel-chrome and nickel-silicon thermocouples is within $\pm 1.5^{\circ} \mathrm{C}$. The pressure of the system is measured by the pressure transducer, whose precision is within $\pm 0.5 \%$. The flow rate is measured by wide range venturi flow meters, the precision of which is within $\pm 1 \%$.

\section{Description of the Tests}

A series of tests devoted to validate the efficiency of low pressure reactor passive safety system were performed in the recent years. The experimental program includes two series with altogether eighteen experiments. The experimental series and conditions are listed in Table 2. The first series focus on validation and research of passive core cooling behaviour, such as cold leg LOCA, hot leg LOCA, and the influence of sensitive parameters. The second series study SBO accident and the influence of sensitive parameters on the passive residual heat removal behaviour [5]. In this paper the cold leg LOCA and SBO test results are presented.

3.1. Cold Leg LOCA Test. The passive system is designed to cool the reactor in more than $48 \mathrm{~h}$, and the fluid temperature in the tank should be less than $80^{\circ} \mathrm{C}$, when the LOCA accident occurs. The motivation of cold leg LOCA test (PSS-11) is to evaluate the safety features of low pressure reactor.

The postulated cold leg LOCA is the one initiated by opening the break simulation valve, causing the system pressure to decrease. Thereafter, the check valve of injection line 
TABLE 1: Major scaling ratios of PSS.

\begin{tabular}{|c|c|c|c|c|c|}
\hline Parameters & Scaling ratio & PSS & Parameters & Scaling ratio & PSS \\
\hline Length (height) & $l_{\mathrm{oR}}$ & $1: 1$ & Diameter & $d_{\mathrm{oR}}$ & $1: 6.71$ \\
\hline Area & $d_{\mathrm{oR}}^{2}$ & $1: 45$ & Volume & $l_{\mathrm{oR}} d_{\mathrm{oR}}^{2}$ & $1: 45$ \\
\hline Core temperature rise & $T_{\mathrm{oR}}$ & $1: 1$ & Velocity & $l_{\mathrm{oR}}^{1 / 2}$ & $1: 1$ \\
\hline Time & $l_{\mathrm{oR}}^{1 / 2}$ & $1: 1$ & Power/volume & $l_{\mathrm{oR}}^{1 / 2}$ & $1: 1$ \\
\hline Heat flux & $l_{\mathrm{oR}}^{1 / 2}$ & $1: 1$ & Core power & $l_{\mathrm{oR}}^{1 / 2} d_{\mathrm{oR}}^{2}$ & $1: 1$ \\
\hline Diameter of rod & 1 & $1: 1$ & No. of rods & $d_{\mathrm{oR}}^{2}$ & $1: 45$ \\
\hline Flow rate & $l_{\mathrm{oR}}^{1 / 2} d_{\mathrm{oR}}{ }^{2}$ & $1: 45$ & Pressure drop & $l_{\mathrm{oR}}$ & $1: 1$ \\
\hline
\end{tabular}

TABLE 2: Typical test matrix.

\begin{tabular}{|c|c|c|}
\hline Experiment & $\begin{array}{c}\text { Condition } \\
\text { (Break location, break size, and water } \\
\text { level and temperature in tank) }\end{array}$ & Objectives \\
\hline \multicolumn{3}{|l|}{ First series } \\
\hline PSS-11 & Cold leg, $22 \mathrm{~mm}, 23 \mathrm{~m}, 32^{\circ} \mathrm{C}$ & $\begin{array}{l}\text { Validation of passive core } \\
\text { injection }\end{array}$ \\
\hline PSS-12 & Hot leg, $22 \mathrm{~mm}, 23 \mathrm{~m}, 32^{\circ} \mathrm{C}$ & $\begin{array}{l}\text { Validation of passive core } \\
\text { injection }\end{array}$ \\
\hline PSS-13 & Cold leg, $18 \mathrm{~mm}, 23 \mathrm{~m}, 32^{\circ} \mathrm{C}$ & Break size effect \\
\hline PSS-14 & Cold leg, $14 \mathrm{~mm}, 23 \mathrm{~m}, 32^{\circ} \mathrm{C}$ & Break size effect \\
\hline PSS-15 & Cold leg, $10 \mathrm{~mm}, 23 \mathrm{~m}, 32^{\circ} \mathrm{C}$ & Break size effect \\
\hline PSS-16 & Hot leg, $18 \mathrm{~mm}, 23 \mathrm{~m}, 32^{\circ} \mathrm{C}$ & Break size effect \\
\hline PSS-17 & Hot leg, $14 \mathrm{~mm}, 23 \mathrm{~m}, 32^{\circ} \mathrm{C}$ & Break size effect \\
\hline PSS-18 & Hot leg, $10 \mathrm{~mm}, 23 \mathrm{~m}, 32^{\circ} \mathrm{C}$ & Break size effect \\
\hline PSS-19 & Cold leg, $22 \mathrm{~mm}, 18 \mathrm{~m}, 32^{\circ} \mathrm{C}$ & Water level effect \\
\hline PSS-110 & Cold leg, $22 \mathrm{~mm}, 13 \mathrm{~m}, 32^{\circ} \mathrm{C}$ & Water level effect \\
\hline PSS-111 & Cold leg, $22 \mathrm{~mm}, 23 \mathrm{~m}, 22^{\circ} \mathrm{C}$ & Water temperature effect \\
\hline PSS-112 & Cold leg, $22 \mathrm{~mm}, 23 \mathrm{~m}, 42^{\circ} \mathrm{C}$ & Water temperature effect \\
\hline Experiment & $\begin{array}{c}\text { Condition } \\
\text { (Resistance* }{ }^{*} \text { startup mode }{ }^{*} \text {, and } \\
\text { water temperature in tank) }\end{array}$ & Objectives \\
\hline \multicolumn{3}{|l|}{ Second series } \\
\hline PSS-21 & $100 \%$ of prototype, cold startup, $32^{\circ} \mathrm{C}$ & $\begin{array}{c}\text { Validation of passive residual } \\
\text { heat removal }\end{array}$ \\
\hline PSS-22 & $120 \%$ of prototype, cold startup, $32^{\circ} \mathrm{C}$ & Resistance effect \\
\hline PSS-23 & $150 \%$ of prototype, cold startup, $32^{\circ} \mathrm{C}$ & Resistance effect \\
\hline PSS-24 & $100 \%$ of prototype, hot startup, $32^{\circ} \mathrm{C}$ & Startup mode effect \\
\hline PSS-25 & $100 \%$ of prototype, cold startup, $22^{\circ} \mathrm{C}$ & Water temperature effect \\
\hline PSS-26 & $100 \%$ of prototype, cold startup, $42^{\circ} \mathrm{C}$ & Water temperature effect \\
\hline
\end{tabular}

${ }^{*}$ Resistance includes.

Startup mode includes cold startup and hot startup.

Cold startup: the fluid in the PL is cold before the natural circulation is established.

Hot startup: the fluid in the PL is warm before the natural circulation is established.

is actuated automatically. Then the coolant in the tank was injected into reactor through the surge line. The discharge of coolant in the tank causes liquid level to decrease. A scram signal trips, when the pressure at the core outlet is less than $350 \mathrm{kPa}$. Following the S-signal, the reactor is tripped; the reactor coolant pumps coasted down; the feedwater supply of heat exchanger is terminated; the passive residual heat removal line and injection line isolation valves are open.
According to the characteristics of the test, the overall transients of the cold leg LOCA test can be roughly characterized by typical two stages: injection stage and natural circulation stage.

The typical results of cold leg LOCA test are shown in Figures 3 6. Figure 3 shows the core pressure. As the break occurs at the cold leg, the system pressure decreases. The top of tank is open to atmosphere, and the initial liquid level is 


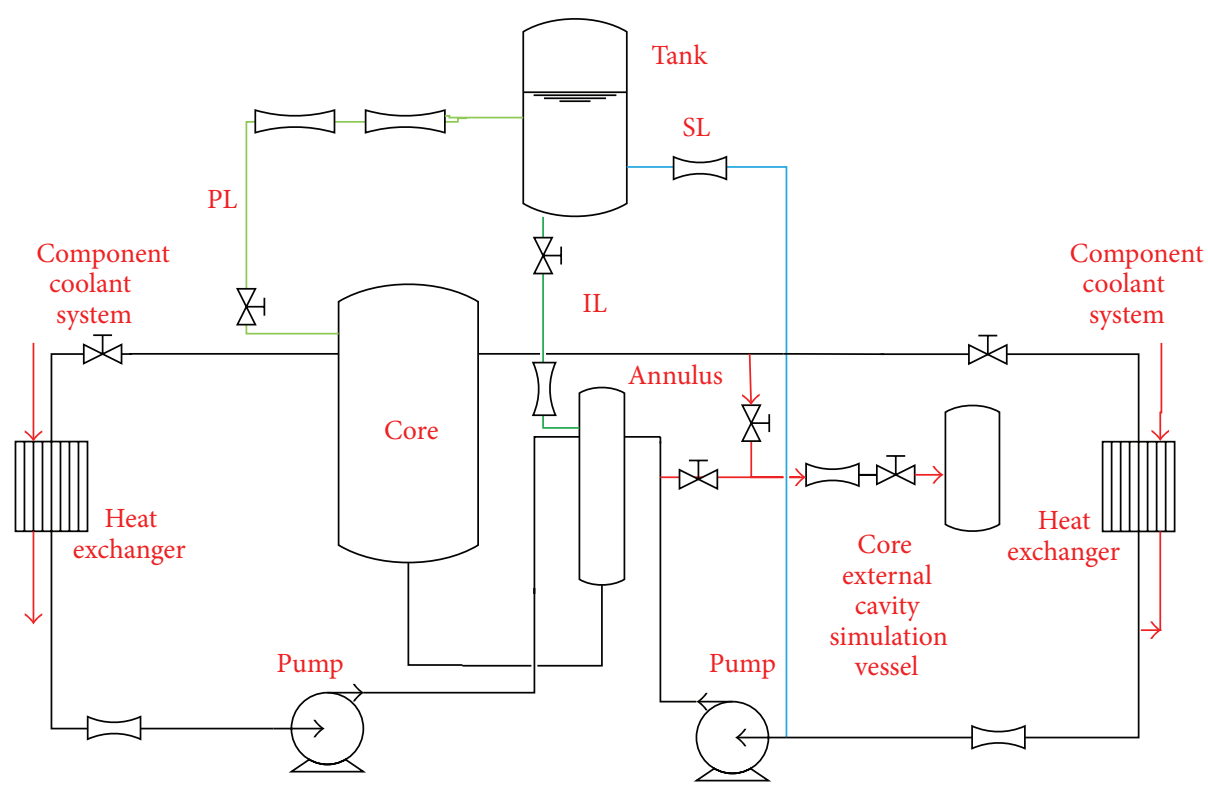

FIGURE 2: Schematic diagram of PSS test facility.

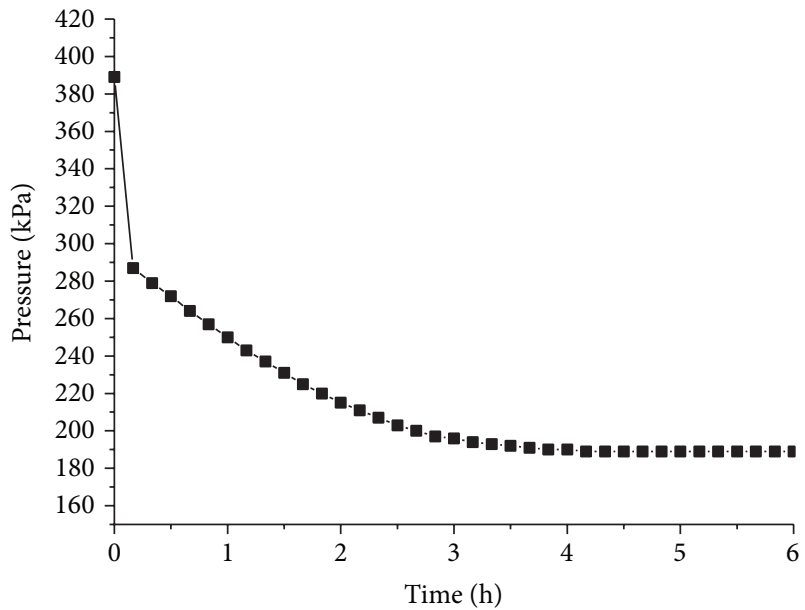

FIgURE 3: The system pressure.

$23 \mathrm{~m}$ (the bottom of tank is $0.15 \mathrm{~m}$ higher than the top of reactor vessel). Therefore the water in the tank can be injected into reactor vessel by gravity.

Figure 4 shows the flow rate of some lines. As the liquid level in the tank descends, the mass flow rate of break, IL, SL, and PL decreases. When the level in the tank is equal to that in the core external cavity simulation vessel, the break flow stops and the natural circulation stage begins.

The temperature of fluid in the core is illustrated in Figure 5. At the initial period, the fluid temperature drops quickly, and the core outlet temperature is lower than that in the inlet. Because most of injection of SL and IL bypasses the core simulation vessel, however the cold water form PL can be injected into the upper plenum. As a result, the reverse flow happens in the core simulation vessel. As the flow rate injected into the core decreases, the temperature begins to

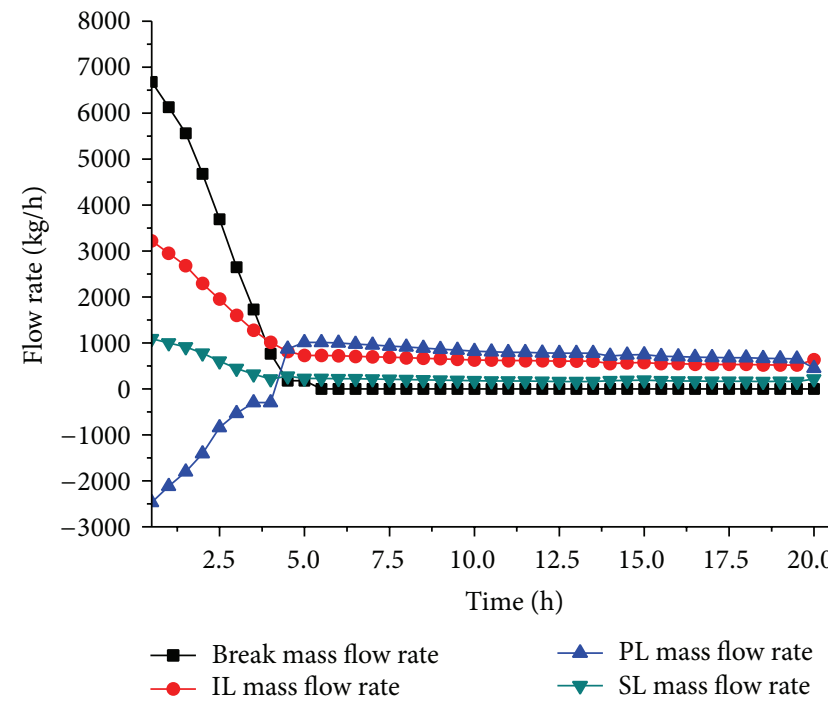

FIgURE 4: The mass flow rate of the main lines.

rise after $2.8 \mathrm{~h}$. When the fluid in the core is stagnant, the temperature in the core inlet and outlet rises to $52.4^{\circ} \mathrm{C}$ and $69.4^{\circ} \mathrm{C}$, respectively. The fluid temperature in the core does not rise until the stable natural circulation is established.

In the natural circulation stage, cold water in the tank is injected into the core through SL and IL. Hot water from the core outlet rises along PL and returns to the tank, which is driven by buoyancy. The core residual heat is removed into the tank by natural circulation. Figure 6 shows the fluid temperatures in tank. When the natural circulation begins (about $4.1 \mathrm{~h}$ after accident happens), the fluid temperature at the top of tank rises. After $48 \mathrm{~h}$, the fluid temperature in the tank is less than $60^{\circ} \mathrm{C}$. Therefore, the adequate core cooling 


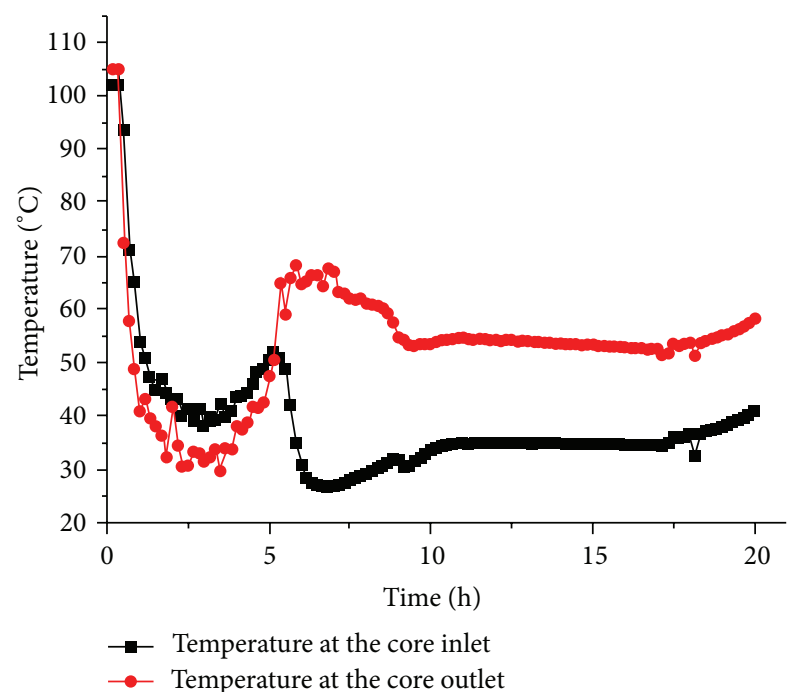

FIGURE 5: Temperature at the core inlet and outlet.

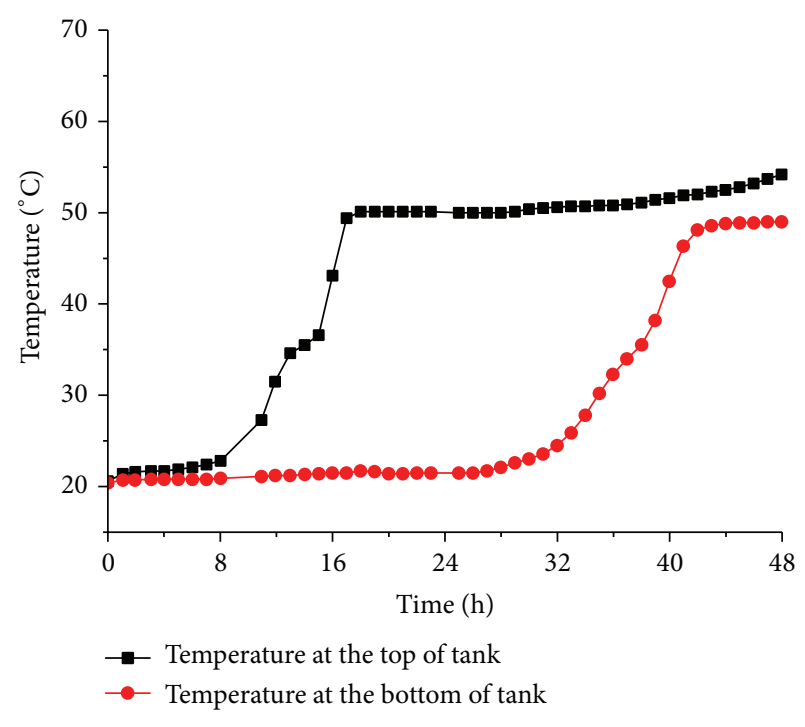

FIgURE 6: Fluid temperatures in tank.

is provided by passive safety system dominantly, during the cold leg LOCA.

3.2. Station Black-Out Accident. The passive residual heat removal system is designed to remove the decay heat in more than $72 \mathrm{~h}$, and the fluid temperature in the tank should be less than $80^{\circ} \mathrm{C}$, when the station black-out accident occurs. The motivation of station black-out accident (PSS-21) is to validate the ability of the passive residual heat removal system.

The postulated station black-out accident is the one initiated by stopping the reactor coolant pumps. Following the accident, the reactor is tripped; only the passive safety systems are operational to remove the core decay heat or to mitigate the consequence of the accident.

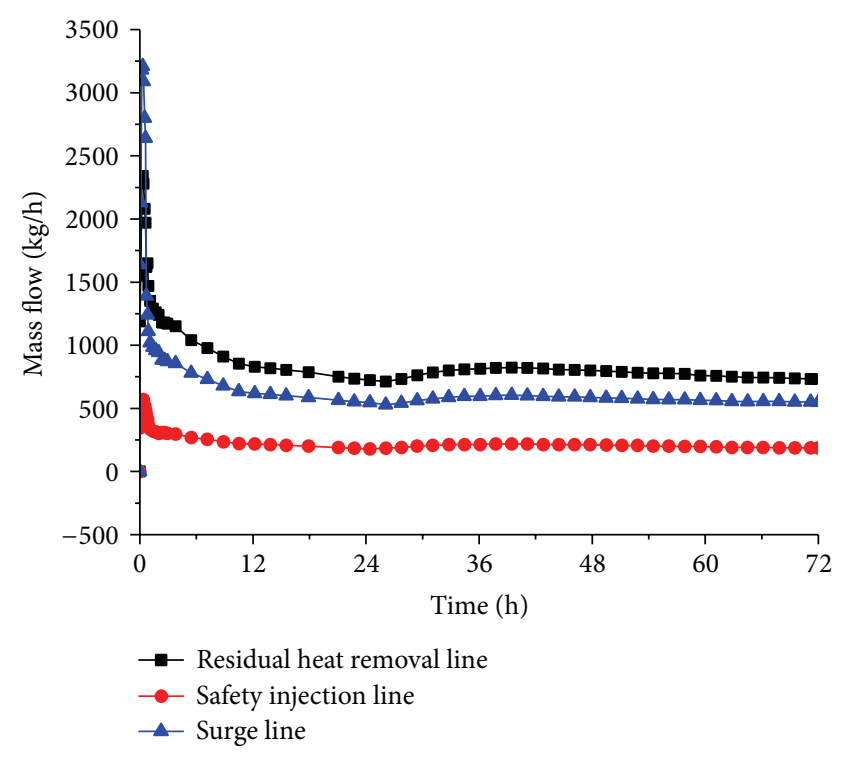

Figure 7: Natural circulation flow rate.

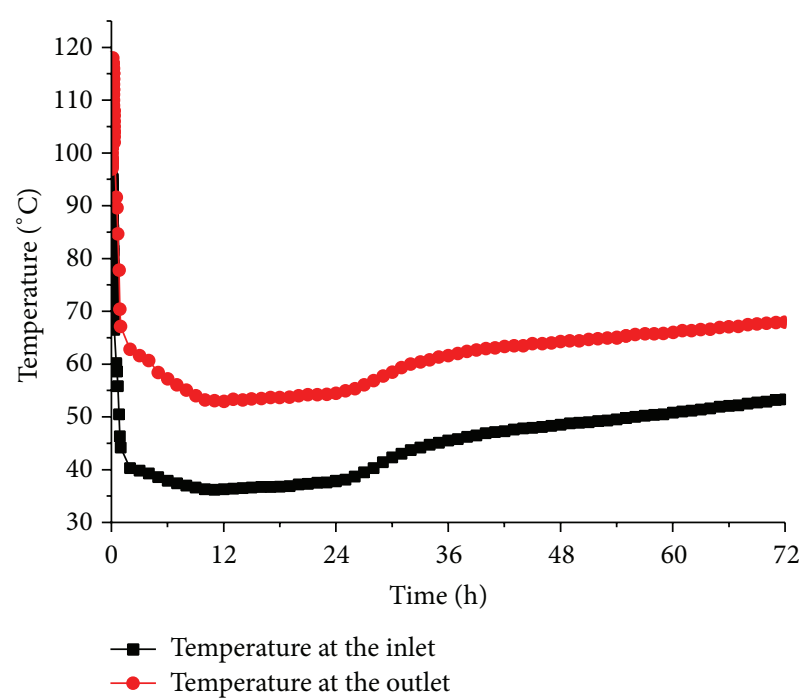

Figure 8: Core inlet and outlet fluid temperatures.

The typical results of station black-out accident test are shown in Figures 7 9. Figure 7 shows the flow rate in the two parallel natural circulation paths. When the station black-out accident is initiated, the natural circulation begins at the time of reactor coolant pumps coastdown. The two parallel natural circulations "core-residual heat removal line-tank-safety injection line-core" and "core-residual heat removal linetank-surge line-core" remove the core decay heat to the tank.

Figure 8 shows the temperature of fluid at the core inlet and outlet. At the beginning of the accident, the natural circulation is unable to remove the core decay heat effectively. And a small portion of coolant at the core outlet evaporates. The two-phase mixture flows into the residual heat removal line, resulting in the increase of natural circulation. The measurements of the flow in the PL line, considered just 


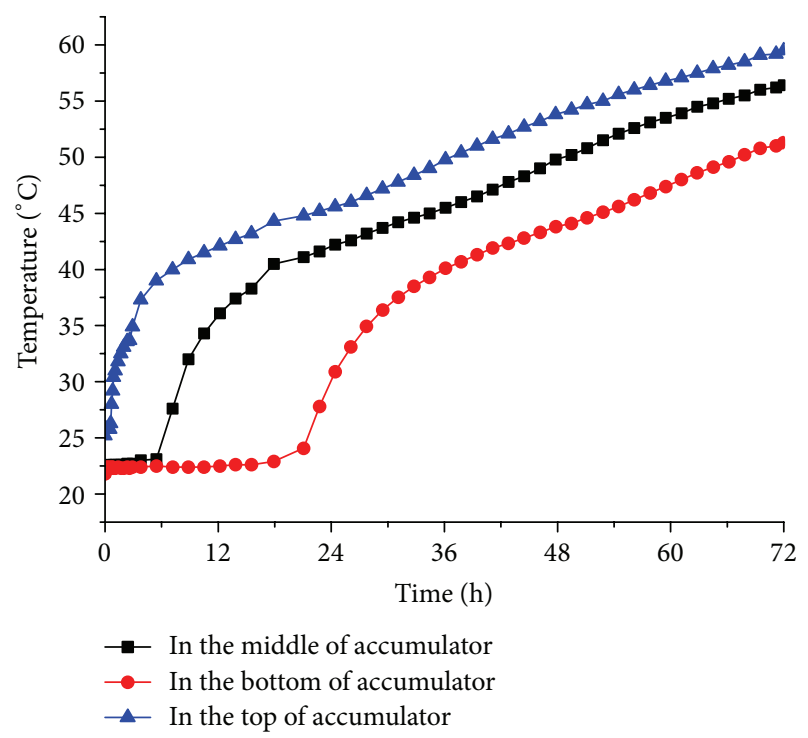

FIGURE 9: Fluid temperatures in tank.

for single-phase flow, are corrected by flow rate of IL and SL. When the natural circulation comes to being stable, the temperature in the core drops rapidly.

Figure 9 shows the temperature of coolant in the tank. The residual heat removal line connects to the top of tank; therefore, the water in the top becomes hot firstly. As the core decay heat is taken to the tank constantly, the cold water in the tank is replaced by hot water gradually. After $72 \mathrm{~h}$, the coolant in the core is still lower than $60^{\circ} \mathrm{C}$. Therefore the experimental results show that the single-phase natural circulation flows steadily into the two parallel loops that it effectively removes the decay heat from the core to tank in more than 72 hours.

\section{Computer Code Simulations}

4.1. Code Description. CATHARE is a system code developed by CEA, EDF, FRAMATOME-ANP, and IRSN for pressurized water reactor (PWR) safety analysis. CATHARE is designed to perform best-estimate analyses of LOCA, operational transients, and other accident scenarios in pressurized water reactor. It can also model phenomena occurring in experimental facility designed to simulate transients in reactor systems. CATHARE modules are based on a six-equation two-fluid model (mass, energy, and momentum equations for each phase), with additional optional equations for noncondensable gases and radiochemical components. A specific treatment of the residual phases exists in order to manage their appearance and disappearance while minimizing convergence problems and with a quasiperfect mass and energy conservation [14]. The version of the code used in this paper is CATHARE V2.1.

4.2. System Model. CATHARE has a flexible modular structure for the thermal-hydraulic modeling in applications ranging from simple experimental test facilities to large and complex installations like nuclear power plants. The main hydraulic components or elements are pipes (1D), volumes (0D), 3D vessel, and boundary conditions, connected to each other by junctions. These models except 3D vessel are based on the 6-equation model, which are two mass balance equations, two momentum balance equations, and two energy balance equations. In CATHARE, the critical flow rate is also determined by the some characteristic of the 6equation model. The physical closure laws play a dominant role in the calculation of critical flow rate. The critical flow rate for nonhomogeneous nonequilibrium two-phase flow is obtained by solving the Jacobian matrix at each time step. The liquid and vapour velocity, obtained by solving the 6-equation system, are then compared with the choking criterion (known as the GROS D'AILLON correlation) [15]. This method is qualified using the results of experimental facilities, such as MOBY DICK facility, BETHSY BREAK NOZZLE characterization tests, and MARVIKEN facility [16]. These facilities are high pressure experiments. In this paper, the break flow rate is validated by experimental data from low pressure:

$$
\begin{aligned}
G_{\mathrm{CR}} & =S \times \sqrt{\frac{20 \times 0.456^{2} \times \rho_{m} \times\left(P-P_{\text {sat }}\left(T_{L}\right)\right)}{\left(\alpha+10 \times 0.456^{2} \times(1-\alpha)\right) \times\left(1+0.012 \times(L / D)+k_{\Delta P s}\right)},}, \rho_{m}=\alpha \times \rho_{g}+(1-\alpha) \rho_{L}, \\
& \left(P-P_{\text {sat }}\left(T_{L}\right)\right) \\
& =\left\{\begin{array}{l}
P-0.9 \times 10^{5} \times\left(\frac{T_{\text {Leq }}+17.95}{117.8}\right)^{1 / 0.223}, \quad \text { if } T_{L}<T_{\text {sat }}(P), \\
\frac{P}{10}, \\
T_{\text {Leq }}=T_{L}+\frac{\left(H_{V}-H_{L}\right) \times \alpha \times \rho_{V}}{\rho_{m} \times \mathrm{CP}_{L}},
\end{array}\right.
\end{aligned}
$$




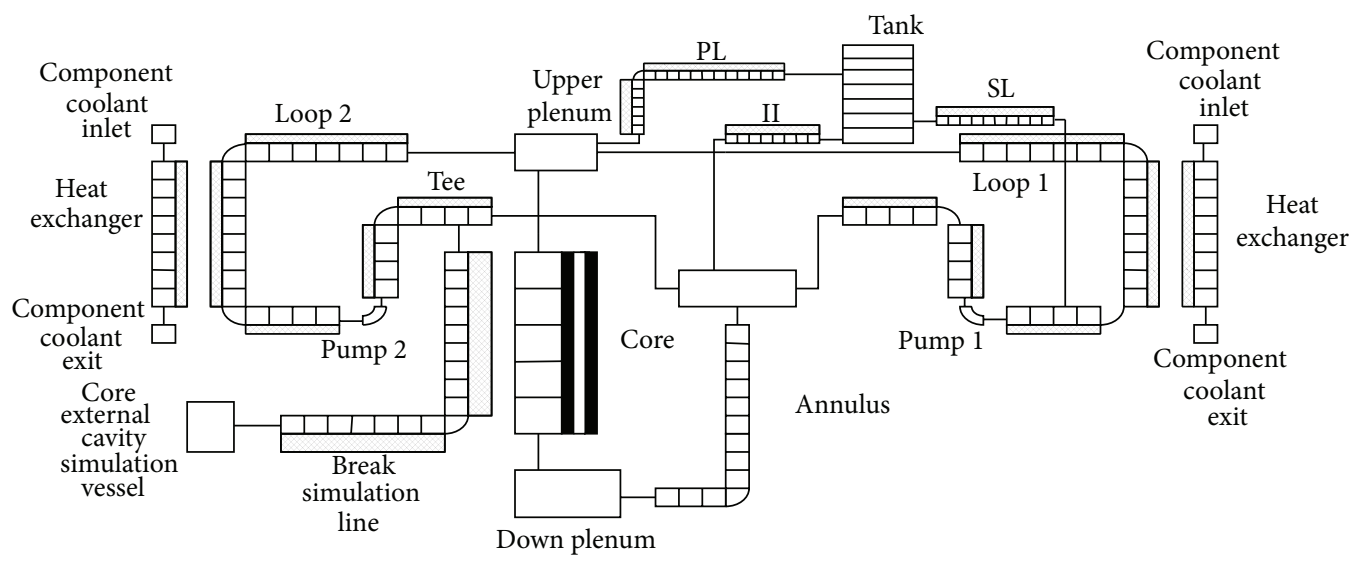

FIGURE 10: CATHARE nodalization diagram of the PSS facility.

where $G_{C R}$ is the critical flow rate choking criterion, $S$ is the break area, $\rho_{m}$ is the mean density, $\rho_{g}$ is the gas density, $\rho_{L}$ is the liquid density, $T_{\text {Leq }}$ is the equilibrium temperature (after steam condensation), $T_{L}$ is liquid temperature, $T_{g}$ is the gas temperature, $P$ is the pressure, $H_{L}$ is the liquid enthalpy, $H_{g}$ is the gas enthalpy, $\alpha$ is void fraction, and $\mathrm{CP}_{L}$ is the liquid specific heat.

In this paper the core and bypass are modeled with $1 \mathrm{D}$ pipes, and the WALL is used to model the power produced by the electrically heated rods and the heat loss of test facility. The upper plenum, lower plenum, and tank are modeled by $0 \mathrm{D}$ volume. TEE + AXIAL+ BCONDIT is used to model the break. Figure 10 illustrates a schematic nodalization of the major elements of the PSS test facility for CATHARE simulation.

\subsection{Calculation Results}

4.3.1. Calculation of the Initial Steady State. At first, a steady state calculation with constant boundary conditions was performed for each test. With help of these calculations, the temperature and pressure distribution, the heat losses, the pressure losses, and the water level were adjusted. When the stable conditions are reached, the steady state calculation is stopped. The main parameters obtained at the end of steady state calculation are compared with the experimental data shown in Table 3. The small difference between the calculation result and the experimental data remains below the sensors uncertainties. Therefore, we can consider that there is a good agreement between CATHARE code predictions for the initial steady state.

4.3.2. Calculation of Transient State. The transient calculation results of cold leg LOCA test are compared with experimental data in Figures 11 13. The comparison of break flow rate is shown in Figure 11. We can see that the calculated break flow rate is in acceptable agreement with experimental data. For low pressure and highly subcooled inlet conditions, the

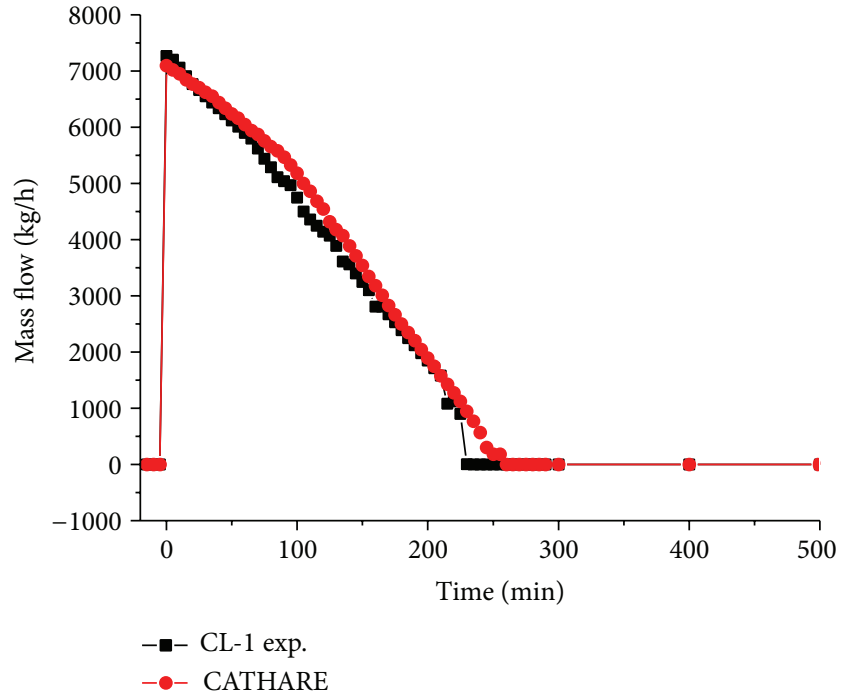

FIGURE 11: The break flow rate.

break flow rate is obtained by solving the Bernoulli equation, and CATHARE can predict it accurately. There is a little discrepancy, which occurs at the end of injection stage. As for the instrumental error, the small break flow rate cannot be monitored by the wide range venturi flow meter.

Figure 12 illustrates the calculated system pressure, which shows reasonable agreement with the experimental data, owing to the good predicted break mass flow rate. During the transition between injection stage and natural circulation stage, the main phenomenon is that the flow reverses in passive residual heat removal line. It is also predicted well by CATHARE as shown in Figure 13. In addition, the other calculated system parameters, such as the temperature of coolant at the core inlet and outlet, the IL mass flow rate, SL mass flow rate, and water level in tank, are in accordance with experimental data. 
TABLE 3: Measured and calculated initial conditions.

\begin{tabular}{lcccc}
\hline Parameter & Unit & Test & Calculation & Error \% \\
\hline Core power & $\mathrm{kW}$ & 600 & 600.5 & 396.3 \\
Pressure & $\mathrm{kPa}$ & 398.0 & 4.396 & -0.43 \\
Loop 1 flow rate & $\mathrm{kg} / \mathrm{s}$ & 4.339 & 4.401 & 1.3 \\
Loop 2 flow rate & $\mathrm{kg} / \mathrm{s}$ & 4.354 & 91.0 & 1.1 \\
Core inlet fluid temperature & ${ }^{\circ} \mathrm{C}$ & 91.2 & 98.6 & -0.22 \\
Core outlet fluid temperature & ${ }^{\circ} \mathrm{C}$ & 98.0 & 22.8 & 0.61 \\
Water level in tank & $\mathrm{m}$ & 23.0 & -0.87 \\
\hline
\end{tabular}

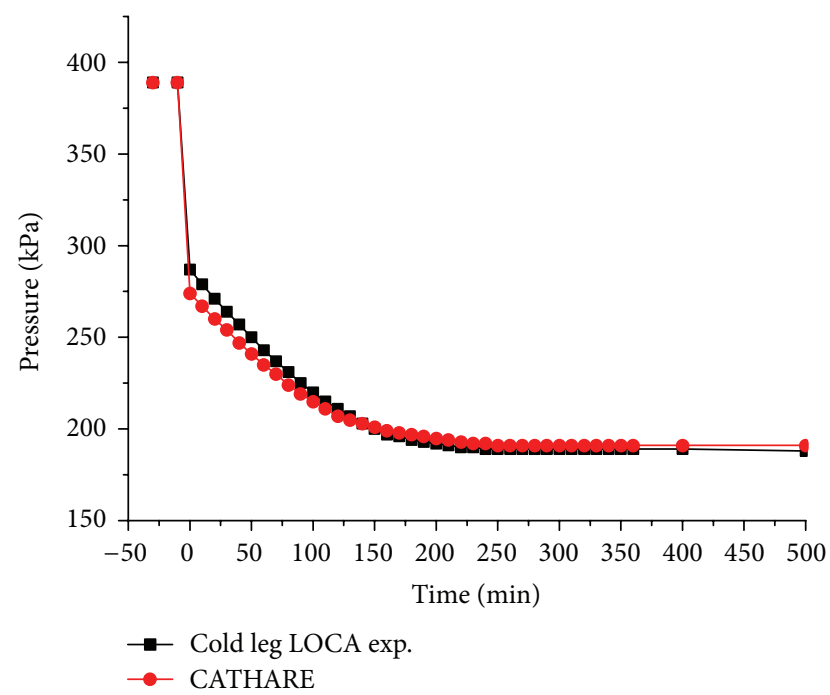

FIgURE 12: The system pressure.

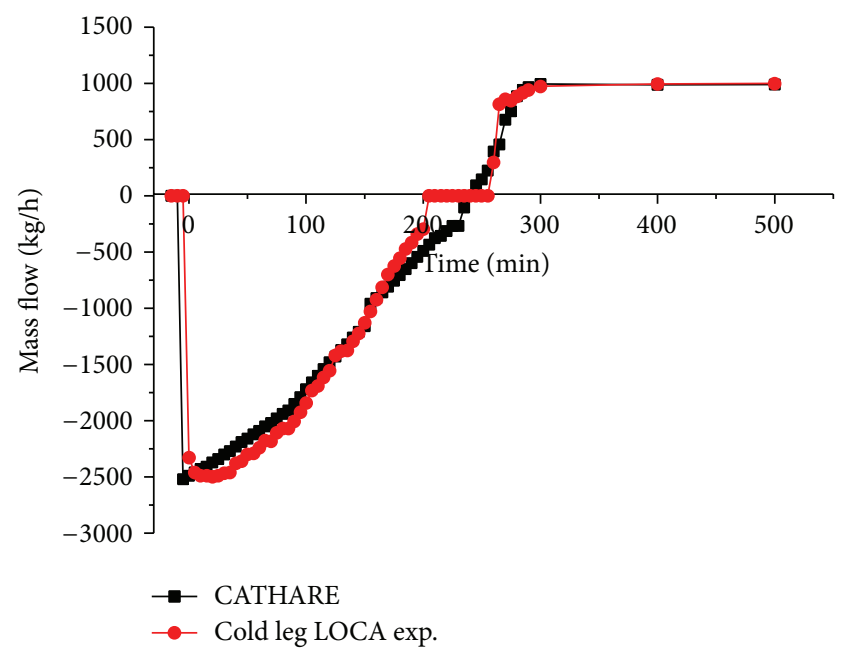

Figure 13: The PL flow rate.

\section{Conclusions}

The designed passive engineered safety systems are an important part of the low pressure reactor. The passive safety characteristics of the reactor following several safety related events have been experimentally investigated in the
PSS test facility. In case of LOCA and SBO accident, the transient trend of the reactor primary loop, emergency core cooling system, and passive residual heat removal system are studied. In the cold leg LOCA test, the water level is enough for passive injection driven by gravity. After the injection stage stops, the natural circulation is established to remove the decay heat to tank continuously. During the station black-out accident, the natural circulation effectively removes the decay heat from the core to tank in more than 72 hours. In addition, the best-estimate thermal hydraulic code, CATHARE V2.1, has been assessed against cold leg LOCA test. The calculation results show that CATHARE predicts the break flow rate accurately for low pressure and highly subcooled inlet conditions. And CATHARE is fully able to calculate the overall scenario observed in the cold leg LOCA test. The calculated parameters are in acceptable agreement with the experimental data.

\section{Nomenclature}

PSS: Passive safety system

LOCA: Loss-of-coolant accident

SBO: Station black-out

PL: $\quad$ Passive residual heat removal line

SL: $\quad$ Surge line

IL: Injection line.

\section{Conflict of Interests}

The authors declare that there is no conflict of interests regarding the publication of this paper.

\section{References}

[1] International Atomic Energy Agency, "Passive Safety Systems and Natural Circulation in Water Cooled Nuclear Power Plants," IAEA-TECDOC-1624.

[2] L. Enchavarri, A General Description of AP1000 Advanced Passive Nuclear Power Plant.

[3] Korea Hydro \& Nuclear Power Corporation, "Standard safety analysis," Tech. Rep. APR1400, Korea Hydro \& Nuclear Power Corporation, Seoul, South Korea, 2002.

[4] Y. Tujikura, T. Oshibe, K. Kijima, and K. Tabuchi, "Development of passive safety systems for Next Generation PWR in Japan," Nuclear Engineering and Design, vol. 201, no. 1, pp. 61-70, 2000.

[5] H. C. Kim, Y.-J. Chung, K. H. Bae, and S. Q. Zee, "Safety analysis of SMART," in Proceedings of the International Conference 
on Global Environment and Advanced Nuclear Power Plants (GENES4/ANP '03), Kyoto, Japan, September 2003.

[6] J. M. Collado, "Design of the reactor pressure vessel and internals of the IRIS integrated nuclear system," in Proceedings of the International Congress on Advanced Nuclear Power Plants, Cordoba, Spain, 2003.

[7] J. N. Reyes Jr., J. Groome, B. G. Woods et al., "Testing of the multi-application small light water reactor (MASLWR) passive safety systems," Nuclear Engineering and Design, vol. 237, no. 18, pp. 1999-2005, 2007.

[8] M. T. Friend, R. F. Wright, R. Hundal, L. E. Hochreiter, and M. Ogrins, "Simulated AP600 response to small-break lossof-coolant-accident and non-loss-of-coolant-accident events: analysis of SPES-2 integral test results," Nuclear Technology, vol. 122, no. 1, pp. 19-42, 1998.

[9] R. F. Wright, "Simulated AP1000 response to design basis small-break LOCAevents in APEX-1000 test facility," Nuclear Engineering and Technology, vol. 39, no. 4, pp. 287-298, 2007.

[10] Y. Kukita, T. Yonomoto, H. Asaka et al., "ROSA/AP600 testing: facility modifications and initial test results," Journal of Nuclear Science and Technology, vol. 33, no. 3, pp. 259-265, 1996.

[11] T. Yonomoto, Y. Kukita, and R. R. Schultz, "Heat transfer analysis of the passive residual heat removal system in ROSA/AP600 experiments," Nuclear Technology, vol. 124, no. 1, pp. 18-30, 1998.

[12] L. Xun and P. Chuanxin, "Low Pressure Reactor Passive Safety System integrated simulation," Test Analysis Report, NPIC, 2009.

[13] M. Ishii and I. Kataoka, Similarity Analysis and Scaling Criteria for LWRs Under Single Phase and Two-Phase Natural Circulation, NUREG/CR-3267, ANL-83-32, Argonne National Laboratory, 1983.

[14] G. Lavialle, "CATHARE2 V2.5_1: User Guidelines, DER/SSTH/ LDAS/EM/2005-034," 2005.

[15] G. Lavialle, CATHAREV2.5_l: User Manual DER/SSTH/LDAS/ EM/2005-035, 2005.

[16] F. Barre and M. Bernard, "The CATHARE code strategy and assessment," Nuclear Engineering and Design, vol. 124, pp. 257284, 1990. 


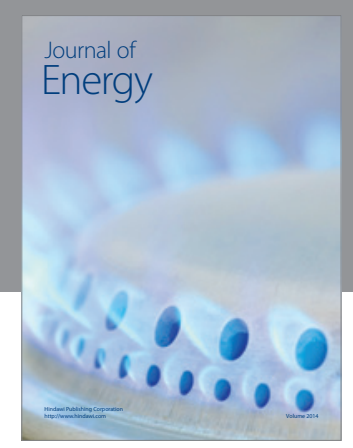

Journal of

Industrial Engineering
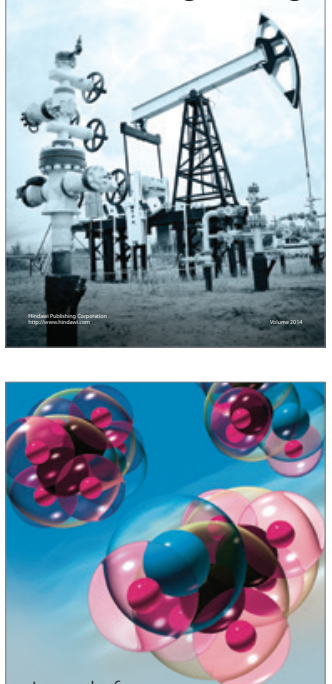

Fuels
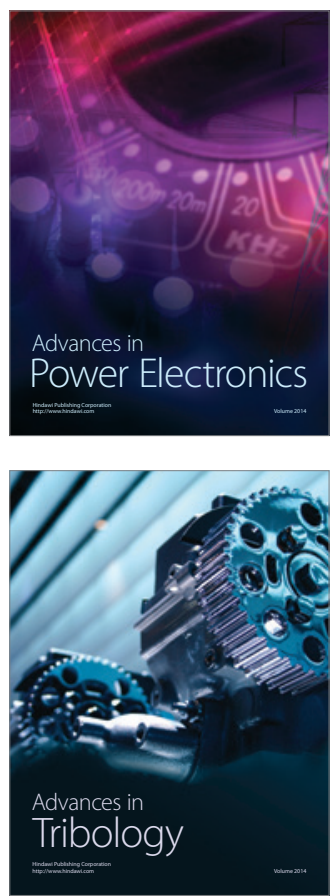

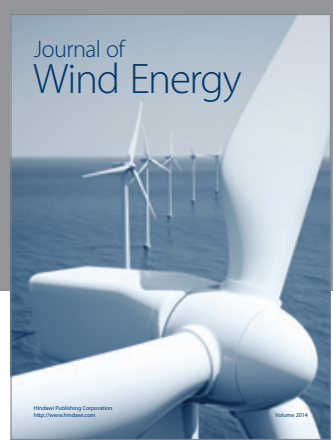

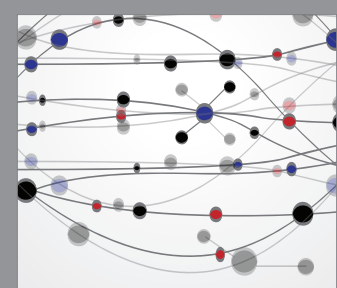

The Scientific World Journal

Submit your manuscripts at http://www.hindawi.com

Journal of

Structures
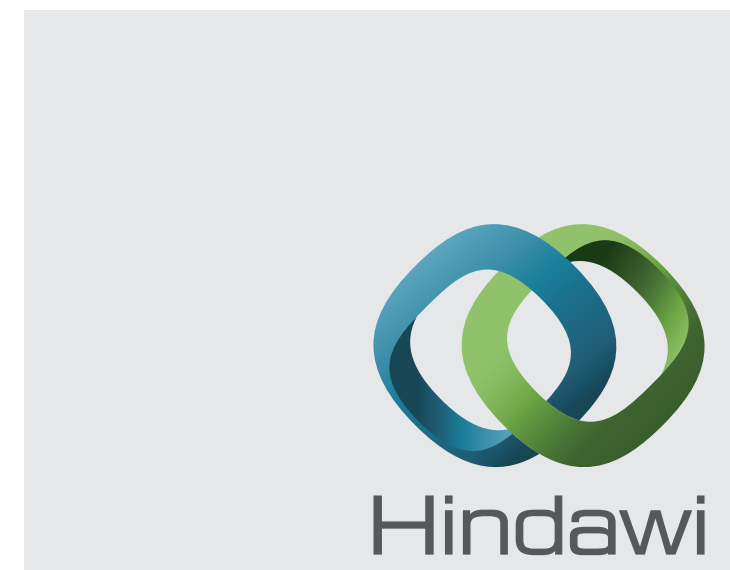

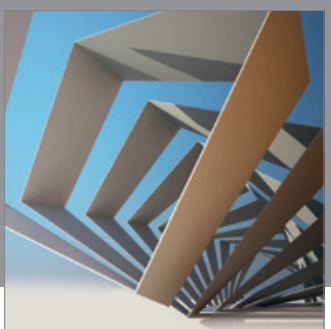

Rotating

Machinery
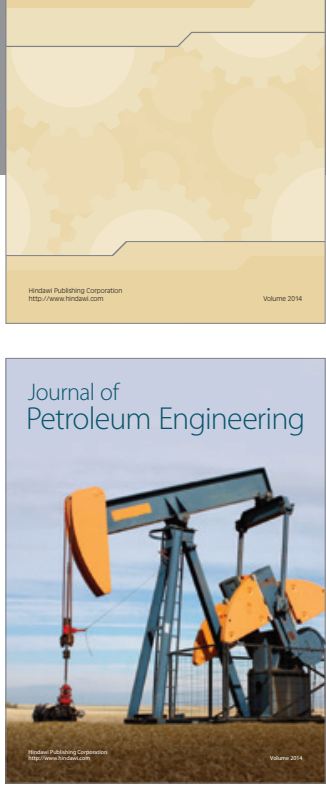

Journal of

Solar Energy
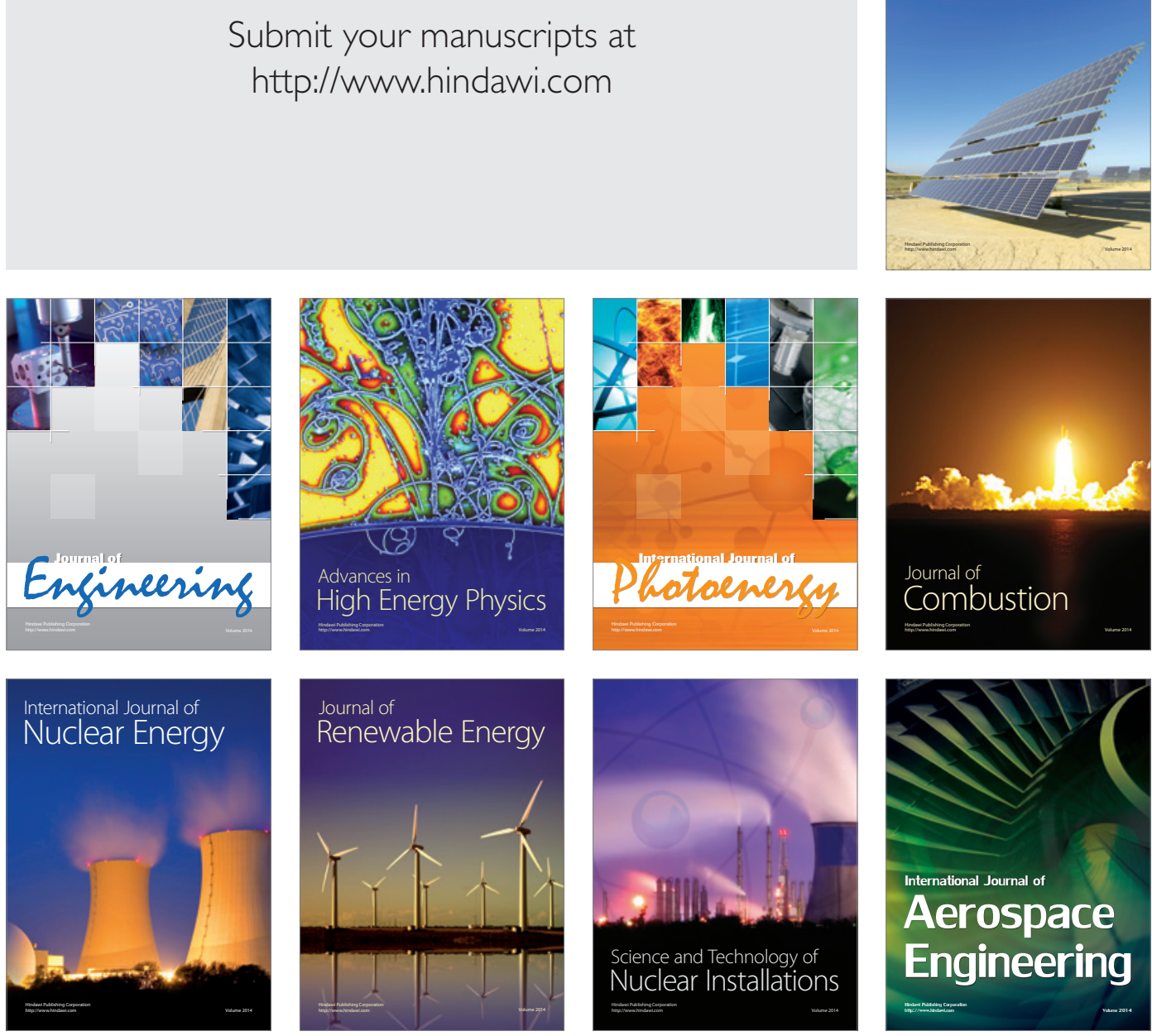